\title{
STUDY OF COMPUTED TOMOGRAPHY (CT) SCAN FINDING IN NEUROFIBROMATOSIS TYPE 2
}

\author{
Kh. Mani Singh ${ }^{1}$, Kh. Vyas $^{2}$ \\ ${ }^{1}$ Assistant Professor, Department of Radiodiagnosis, JNIMS, Imphal. \\ ${ }^{2}$ Assistant Professor (Neurosurgery), Department of Surgery, JNIMS, Imphal.
}

\begin{abstract}
Computed tomography (CT) scan finding in neurofibromatosis type 2 in the case of bilateral acoustic schwannomas and multiple meningiomas, which fulfilled the National Institute of Health ( $\mathrm{NIH}$ ) Consensus Committee diagnostic criteria. Computed Tomography (CT) scan is without doubt the most valuable and informative neuro-radiological method in the diagnosis of acoustic schwannoma.

\section{METHOD}

In our study, we prospectively analysed twenty one patients presenting with diminished hearing with presence of cerebellopontine angle mass diagnosed radiologically as acoustic schwannoma during January 2013 to December 2014 in the multislice computed tomography scan imaging.
\end{abstract}

\section{CONCLUSION}

Neurofibromatosis type 2 is an autosomal dominant inheritance disorder. Hence, diagnosis of such cases needs screening of first degree relatives for early diagnosis to be sought for surgically correctable treatment.

\section{KEYWORDS}

CT Scan, Acoustic Schwannomas, Neurofibromatosis Type-2, Meningiomas.

HOW TO CITE THIS ARTICLE: Kh. Mani Singh, Kh. Vyas. "Study of Computed Tomography (CT) scan finding in neurofibromatosis type 2." Journal of Evolution of Medical and Dental Sciences 2015; Vol. 4, Issue 105, December 31; Page: 17062-17065,

DOI: $10.14260 /$ jemds/2015/2585

\section{INTRODUCTION}

Neurofibromatosis type 2 also known as NF-2 is an autosomal dominant inherited disease of genetic disorder characterised by bilateral acoustic schwannomas in over 90 percent of cases. ${ }^{1}$ it is distinctly separated clinically and radiologically from Neurofibromatosis type 1. It occurs approximately 1 in 50,000 live births. Intracranial lesions such as cranial nerve VIII Schwannomas and Meningiomas often multiple are common CNS lesions found in NF-2.2

\section{DIAGNOSTIC CRITERIA}

The National Institute of Health (NIH) Consensus Committee has defined a set of diagnostic criteria for Neurofibromatosis type 2 if the patient has one of the following criteria. ${ }^{3}$

1. Bilateral masses of eighth cranial nerve (biopsy not needed).

2. A first degree relative of NF-2 plus either a single 8th Cranial nerve mass or any two of the following Schwannoma, Neurofibroma, Meningioma, Glioma or Juvenile Posterior subcapsular lens opacity.

\section{PATHOLOGY AND IMAGING}

Acoustic Schwannomas are benign tumours that arises from the nerve sheath of eight cranial nerve usually from vestibular division ${ }^{4}$ and located within the internal auditory canal (IAC) and cerebellopontine angle (CPA). Classically it arises at the junction of commonly near the porus acusticus representing CPA mass. Acoustic schwannoma usually tend to show iso to

Financial or Other, Competing Interest: None.

Submission 07-12-2015, Peer Review 08-12-2015,

Acceptance 18-12-2015, Published 31-12-2015.

Corresponding Author:

Dr. Kh. Mani Singh,

Sagolband Tera Bazar,

Sapam Leirak,

Imphal-795001,

Manipur.

E-mail: khaidemmanisingh@yahoo.in

DOI:10.14260/jemds/2015/2585 hypodense CPA mass compared to brain in non-contrast CT and show strong enhancement following contrast administration. They are located at or in the IAC and produces erosion of the canal. It does not produce hyperostosis. Bilateral acoustic schwannomas are the hallmark of NF-2 and diagnostic of this condition. ${ }^{2}$

Meningioma is the most common non-glial primary CNS tumour, originate from the specialised meningothelial cells in arachnoid granulations called arachnoid cap cells and also from dural fibroblast sometimes. Multiple meningiomas occurs in $1 \%$ to $9 \%$ of imaging cases. Neurofibromatosis type 2 is the major genetic condition that predisposes to meningioma formation, which are often multiple. ${ }^{2}$ Meningiomas are usually dural based homogenous iso to hyperdense in CT before contrast relative to brain parenchyma and enhancement is usually homogenous after contrast infusion. ${ }^{3}$

\section{MATERIAL AND METHODS}

Patients were included in the study who came with complaints of hearing loss during January 2013 to December 2014 in JNIMS, Imphal, who were sent for CT scan examination. They were evaluated with otolaryngology examination initially with audiometry. In our study, we prospectively analysed twenty one patients presenting with diminished hearing with sensory neural deafness. Patient with head injury are not included in the study. Multislice CT examination were performed in all the cases in both plain and contrast enhancing study.

\section{RESULT}

Twenty one patients were analysed which show cerebellopontine angle mass characteristic of acoustic schwannoma with male-female ratio of $2: 1$. All the tumours show intense contrast enhancement. Two female patients out of twenty one cases had bilateral acoustic schwannoma with a younger age group of 27 and 31 years, which fulfilled the diagnostic criteria of National Institute of Health Consensus Committee. One patient shows bilateral CP angle isodense masses of marked homogenous contrast enhancement eccentrically located in the respective internal auditory canal (Fig. 1 and 2) with displacement of adjacent cerebellar cortex. 
Brain stem is slightly rotated towards the right side with widening of left CP angle. The size of the lesions measured $2.2 \mathrm{~cm} \times 2 \mathrm{~cm}$ in axial dimension on the left (Fig. 2) with internal auditory acoustic meatus of $8 \mathrm{~mm}$ and $1 \mathrm{~cm} \times 0.8 \mathrm{~cm}$ on the right with internal acoustic meatus of $9 \mathrm{~mm}$ (Fig. 3). These findings are consistent with bilateral acoustic schwannomas having recurrence/residual on the right side which made a diagnosis of Neurofibromatosis type 2 .

In another patients shows in NCCT as ill-defined isodense mass lesion in the right cerebellar hemisphere with mass effect compression effacement of 4th ventricle (Fig. 4). Contrast Enhanced CT (CECT) shows a well-defined coneshaped homogenous contrast enhancing lesion $(23 \mathrm{~mm} \times$ $22 \mathrm{~mm}$ ) in the right Cerebellopontine Angle (CPA) eccentrically located in the right Internal Auditory Canal (IAC) displacing adjacent cerebellar cortex posteromedially with compression effacement of 4 th ventricle with widening of CPA suggested acoustic schwannoma (Fig. 5). Similar characteristic smaller contrast enhancing CPA mass on the left side with extension into IAC is present (Fig. 6) In the Bone window setting, Bilateral IAC are widen with erosion of IAC on the left side without abnormal hyperostotic bony lesion (Fig. 7). Widen right internal auditory canal measures $8.4 \mathrm{~mm}$ (Fig. 8).

Multiple discrete, well defined, varying sizes of rounded and semilunar shaped with broad dural based hyperdense solid masses with homogenous intense contrast enhancement lying over the right cerebellar hemispheric convexity and along the posterior border of petrous bones bilaterally as well as in the interhemispheric fissure attaching falx cerebri with mass effect (Fig. 9).

These indicated respectively Bilateral Acoustic Schwannomas (Neuromas) and multiple Meningiomas. Depending on clinical and imaging findings the diagnosis of "Neurofibromatosis type 2" was made.

\section{DISCUSSION}

CT scan examination with contrast enhancement by iodinated intravenous contrast medium has virtually replaced invasive radiological investigation in the diagnosis of acoustic neuroma. After contrast enhanced CT, the accuracy of CT in the diagnosis of acoustic tumours, which extend into the cranial cavity is about 97 to 100 percent. $^{5}$

Neurofibromatosis type 2 also known as NF-2 is an autosomal dominant inherited disease of genetic disorder characterised by bilateral acoustic schwannomas in over 90 percent of cases. ${ }^{1}$ It is distinctly separated clinically and radiologically from Neurofibromatosis type I. It occurs approximately 1 in 50,000 live births. Intracranial lesions such as cranial nerve VIII Schwannomas and Meningiomas often multiple are common CNS lesions found in NF-2.2

The National Institute of Health (NIH) Consensus Committee has defined a set of diagnostic criteria for Neurofibromatosis type 2 if the patient has one of the following criteria. ${ }^{3}$

(1) Bilateral masses of eight cranial nerve (biopsy not needed).

(2) A first degree relative of NF-2 plus either a single8th Cranial nerve mass or any 2 of the followingSchwannoma, Neurofibroma, Meningioma, Glioma or Juvenile Posterior subcapsular lens opacity.

These cases are being represented for the rarity and to highlight the first criteria with associated multiple intracranical meningiomas for the diagnosis of Neurofibromatosis type 2. National Institute of Health (NIH) consensus Committee has defined Bilateral Acoustic Schwannomas are diagnostic of NF-2. Multiple meningiomatosis are frequently associated with NF-2.2
Computed Tomography (CT scan) is without doubt the most valuable and informative neuroradiological method in the diagnosis of Acoustic Neuroma. 6

Classical CT finding of acoustic neuromas are contrast enhancing tumours in the region of $\mathrm{CP}$ angle, contralateral displacement of the 4 th ventricle and non- visualisation of 4 th ventricle. ${ }^{7}$

Erosion and widening of internal acoustic meatus in acoustic neuroma are found in $75 \%$ cases. $^{8}$

Historically Acoustic Schwannoma had been diagnosed on plain radiography and conventional tomography by the presence of widening Internal Auditory Meatus (IAM). Subsequently contrast enhanced thin section CT scanning through posterior fossa had been used looking for enhancing CP angle mass with widening of IAM on bone window setting. ${ }^{9}$ All the findings were present in the presented cases. Intracranial Schwannomas most frequently affect 8th nerve complex and bilateral tumours are the hallmark of NF-2.10

Intracranial Meningiomas found in NF-2 are usually multiple and appear as well circumscribed intensely enhancing extra-axial masses with dural attachment. ${ }^{3}$

\section{CONCLUSION}

Bilateral Acoustic Schwannomas are the hallmark and diagnostic of NF-2. Neurofibromatosis type 2 predisposes to Meningioma formation. Radiological diagnosis of NF-2 was made in these cases based on the presence of these CT findings which fulfilled the diagnostic criteria. Neurofibromatosis is transmitted with autosomal dominant inheritance and has been identified with defects of Chromosome number 22 . Multiple meningiomatosis are frequently associated with NF2. Hence, diagnosis of such cases needs screening of first degree relatives for early diagnosis to be sought for surgically correctable treatment.

\section{NCCT AND CECT OF BILATERAL CP ANGLE MASSES}

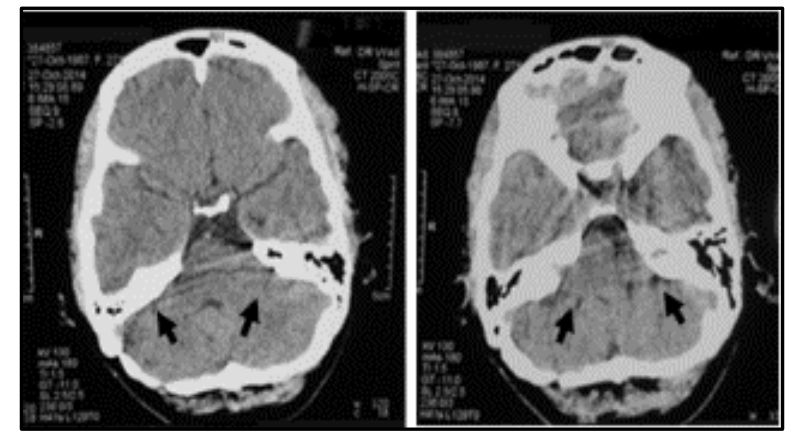

Fig. 1: NCCT-Brain showing Bilateral CP angle isodense mass

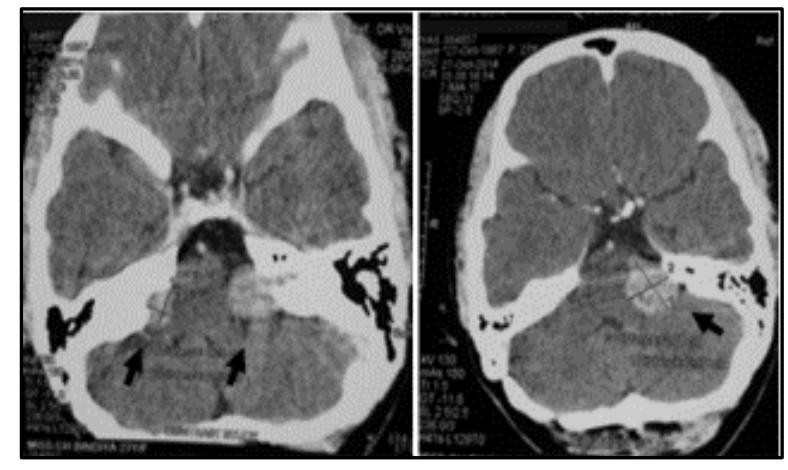

Fig. 2: CECT-Brain showing Bilateral CP angle contrast Enhancing Mass eccentrically located in IAC 



Fig. 3: Bone window setting shows widen bilateral IAC and post craniotomy skull defect

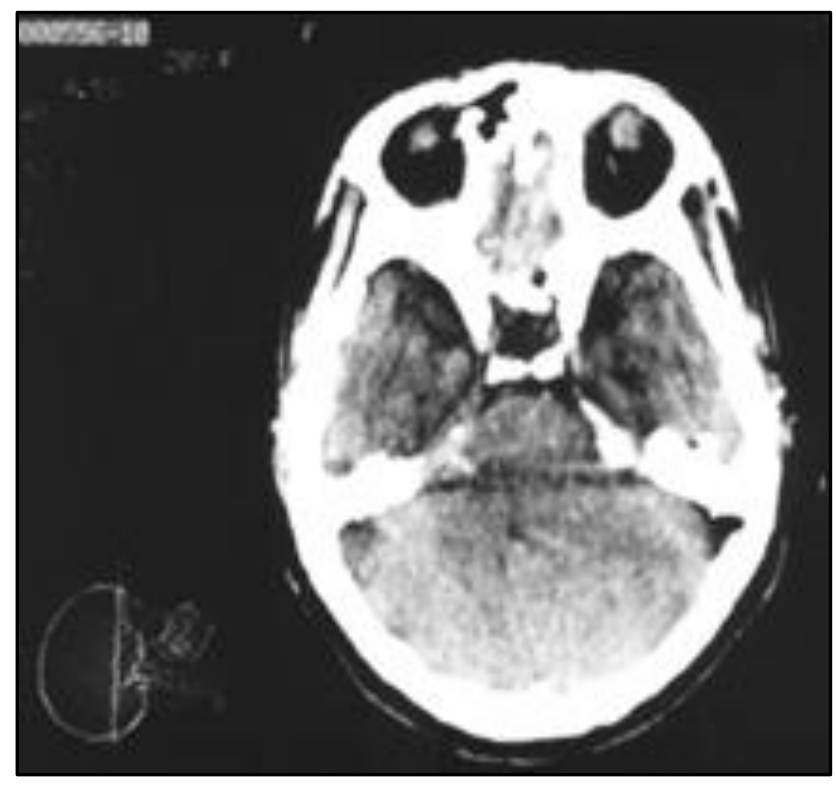

Fig. 4: Axial NCCT Brain through Pons showing extra-axial mass Pons showing Acoustic Schwannoma compressing $4^{\text {th }}$



Fig. 5: Axial CECT Brain through ventricle in Bilateral CP angles

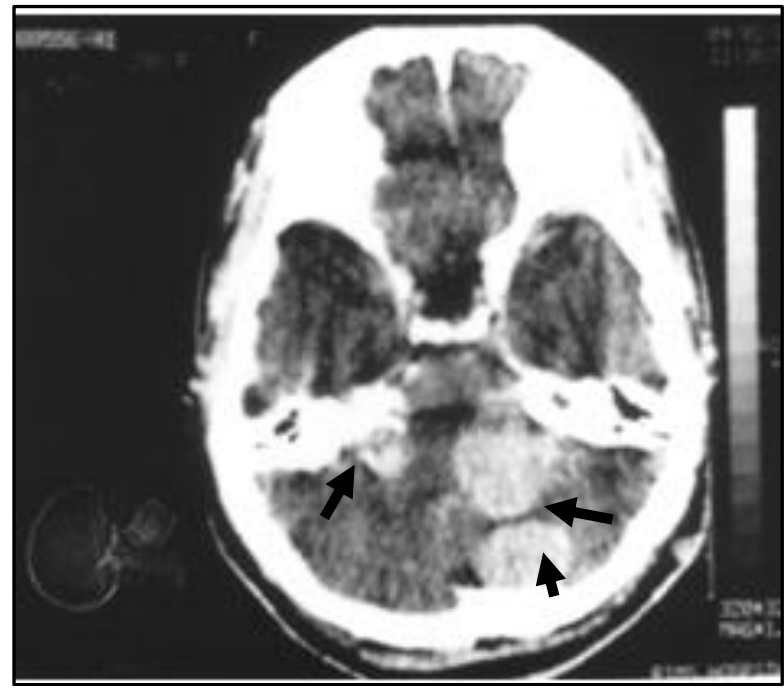

Fig. 6: Axial CECT Brain showing Bilateral Acoustic Schwannomas and associated finding of meningioma in the cerebellar convexity

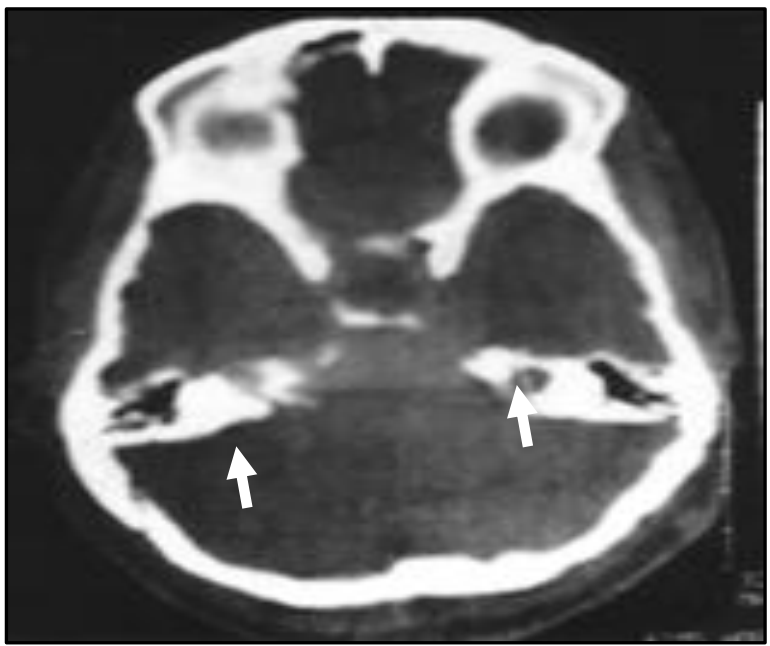

Fig. 7: Axial CT Skull in Bone window setting showing widen Bilateral IACs with erosion on the left

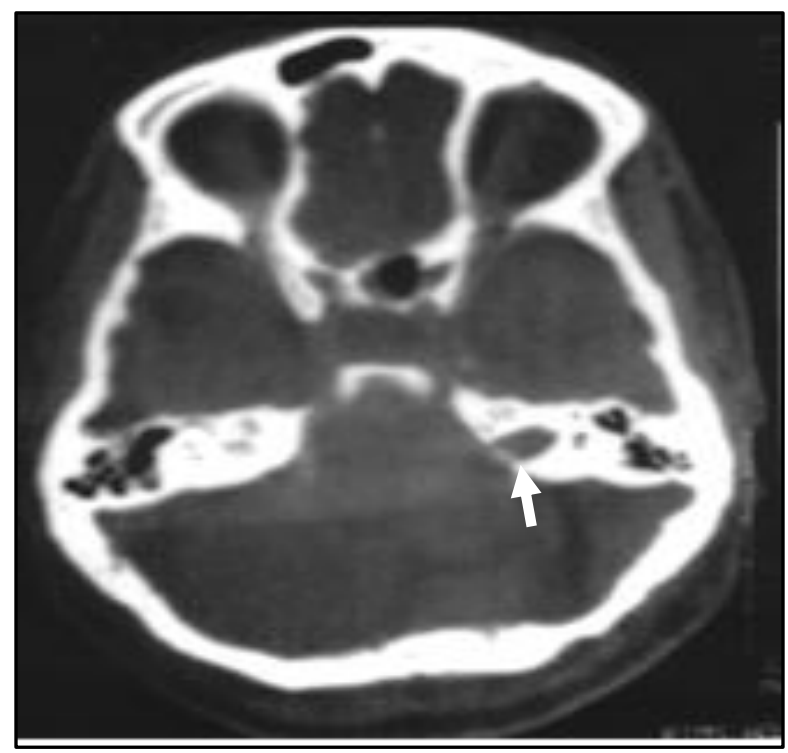

Fig. 8: Axial CT Skull in Bone window setting showing widen right IAC 


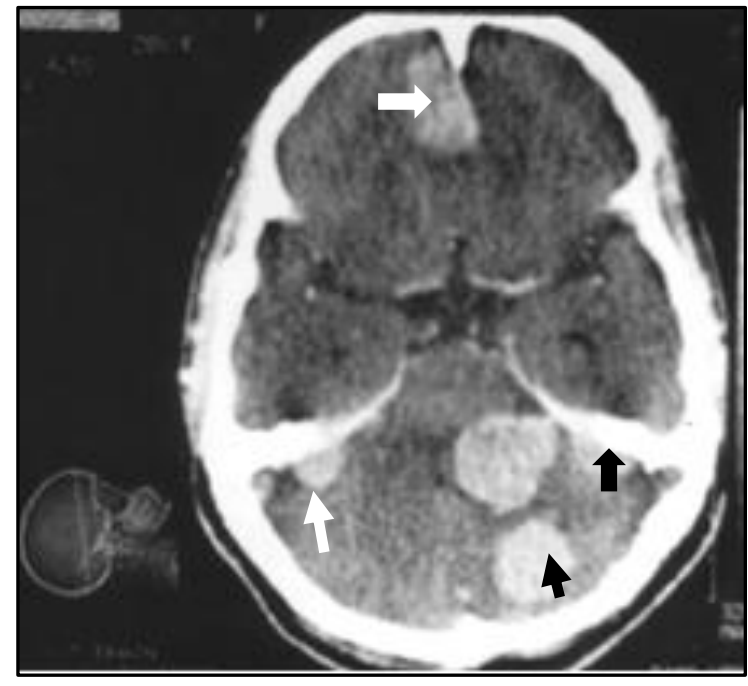

Fig. 9: Axial CECT Brain showing multiple meningiomas in cerebellar convexity, along the petrous ridges and cerebral interhemispheric parasagittal region

\section{REFERENCES}

1. Stephen MS, Mark AI. Tumours of the nervous system. In: Harrison's Principles of Internal Medicine. Fauci, Braunvvald, Isselbacher, Wilson. Martin, Kasper, Hauser, Longo (editors). 14thEdn. vol. 2. New York (USA); Me Graw-Hill: 1998;2398-2409.
2. Osborn Anne G. Diagnostic Neuroradiology. USA; Mosby-year Book Inc: 1994.

3. James GS, Frances MM. Central Nervous System manifestations of the Phakomatosis and other inherited syndromes. In: MRI of the Brain and Spine. Scott W Atlas. 2nd Edn. Philadelphia; Lippincott Pub: 1996;774-802.

4. Goldberg HI. Extra-axial brain tumours. In: Atlas SW, 2nd Ed. Magnetic resonance imaging of the brain and spine. New York Raven Press, 1991;327-377.

5. Ambrose J. Diagnosis of Acoustic Neuroma. Brit J of Radiol 1978;46:1023-1029.

6. Saha NK, Moseley IF. The Diagnosis of Acoustic Neuroma by Computed Tomography. IJR, 1983;37:27-30.

7. Hatam A. Early contrast enhancement of Acoustic Neuroma. Neuroradiol. 1978;17:31-33.

8. Kendall B and Symon L: Investigation of patients presenting with cerebellopontine angle syndrome, Neuroradiology, 1977;13:65-84.

9. Jager R, Rich P. Cranial and Intracranial pathology (I) Intracranial tumours in adults. In: Grainger and Allison's Diagnostic Radiology. Grainger RG, Allison DJ, Adam A, Dixon AK (editors). 4th Edn. vol. 3. London; Churchhill Livingstone: 2001;2325-2340.

10. Pendse NA, Menhani V. Neurofibromatosis 2-A case report. IJR Imaging. 2003;13(I):99-101. 